\title{
English for fire science students - a book review
}

\author{
Petra Čančová \\ Constantine the Philosopher University in Nitra, Slovakia; petra.cancova@ukf.sk
}

English for specific purposes is the way of teaching language the students who may have special requirements and needs in various fields of their professional or possible future professional life. Such students need to focus on specific vocabulary, communication skills or types of expressions. Jaroslava Štefková's book, English for Fire Science Students. Zvolen: Technická univerzita vo Zvolene reflects the engineering level students' needs of university studies in the area of Fire Protection and Safety.

The book is divided into 8 units. Each unit deals with a different topic related to fire protection. The units are focused mostly on vocabulary, its use and development necessary in practice when dealing with specific text and in specific situations. The major part of the book is written in the form of a workbook with a great emphasis on practical exercises and not much as a students' book. The topics of each unit arise from real situations and the texts are from original sources dealing with fire protection.

Each unit consists of various types of study materials and exercises. Firstly, original texts deal with reading comprehension and text-related exercises, e. g. true/false, choosing the correct option, answering the questions, etc. Secondly, you can find there vocabulary and practical exercises such as matching, filling in words, completing sentences, creating questions, word formation, etc.; and translation exercises. Little attention is paid to grammar. Furthermore, a video exercise that uses a relevant terminology and a lot of practical exercises is included in every unit. Each video can be read by its QR code and that is why it is possible to watch it from any place that has the internet connection and at any time. Some video exercises have a glossary included and some provide information about other recommended videos together with a QR code. At the end of the book students find key to all exercises for each unit as well as for video exercises.

The structure of units is not the same. For instance, the first unit starts with a vocabulary exercise in which students have to match jobs with their descriptions followed by other vocabulary exercises. Another part of the unit is a video exercise without glossary, then reading, word formation tasks and a translation exercise. The last task is a free style writing exercise on what had been studied.

On the other hand, the second unit starts with a reading comprehension task, continues with grammar and vocabulary focused tasks and finishes with a video exercise including glossary. In this unit there is no translation exercise.

The book bears a huge amount of specific vocabulary that is presented and practiced in many types of exercises. Students can easily learn and practice the words. An inspirational part are few exercises in certain units that force students to open a web page and fulfil the task. These types of exercises seem to be interactive and can lead students to further studies.

Tasks that deal with translation are nowadays not very frequent or even never presented in students' books or workbooks. Such exercises in this book are a very pleasant change and help for students because through translation, especially very specific terminology, they can fully understand the meaning and see the shades of the meaning, e.g. when searching for the right Slovak equivalent and working with synonyms.

Grammatical tasks are presented without any previous explanation or revision of particular grammatical structures. A brief introduction to each grammatical structure presented within the units or adding an appendix by the end of the book dealing in short with the grammar would be very suitable. Otherwise, during planning his or her lesson, the teacher must have possible problems or questions about the grammar in mind and should be prepared to explain them. 
In contrast to the number of vocabulary exercises, there are not many speaking activities such as roleplays, etc., to encourage students to use the terminology in an active way and practice it in real situations, which is a disadvantage.

Finally, there is no complete glossary of all the words and expressions used in the units. According to the author, it was not possible to translate certain words with an equivalent technical term English language to Slovak. This can be on one hand disappointing and frustrating for students but on the other hand it gives them a unique opportunity to work on their own, personal dictionary created by searching for the right Slovak translation and in this way to learn and remember terminology more effectively than just looking up the word in a list of vocabulary and mechanically getting the immediate direct translation.

To sum up, the aim of the review is to comment on the study book designed for ESP students, specially focused on Fire Science. The book is highly recommended to be used by the teachers teaching ESP in tertiary education and by the students whose study programs deal with Fire Science. Definitely, the book is not dedicated for the students whose level of English is lower than intermediate because it does not offer teaching basic vocabulary and grammatical structures. Due to the lack of the aforementioned issues, this book can be a great help and contribution in teaching ESP. In general, it meets requirements and needs in teaching Fire Protection and Safety and encourages students to develop their language knowledge. 